\title{
Hepatotoxicity Effects of Alcohol Consumption during Paracetamol Therapy of Malaria Patients
}

\author{
Fonny Dinge ${ }^{1}$, Sofa D. Alfian ${ }^{2}$, Rizky Abdulah ${ }^{2}$, Sri A. Sumiwi ${ }^{2}$ \\ ${ }^{1}$ Regional Public Hospital of Abepura, Jayapura, Papua, Indonesia \\ ${ }^{2}$ Department of Pharmacology and Clinical Pharmacy, Faculty of Pharmacy, Universitas Padjadjaran, \\ Jatinangor, West Java, Indonesia
}

\begin{abstract}
The risk of paracetamol induced hepatotoxicity could increase with alcohol consumption. Paracetamol was usually given to tropical malaria patients to treat fever. The aim of this study was to determine the hepatotoxicity effect of alcohol consumption in malaria tropica patients receiving paracetamol. This study was a cross-sectional study which was conducted during April-June 2015 at a hospital in Jayapura, Indonesia. The datawere obtained from questionnaires and medical records. Alcohol status was determined by Short Michigan Alcoholics Screening Test (SMAST) questionnaire. Level of ALT, AST and bilirubin were observed before and after receiving paracetamol therapy for 5 days. Based on the results, the ALT and bilirubin levels of alcoholic group were higher than in non-alcoholic. However, chi-square test showed that alcohol status did not have a significant influence in ALT, AST, and bilirubin levels. Otherwise, logistic regression analysis showed that age gave a significant effect on AST level $(\mathrm{P}=0.067)$.
\end{abstract}

Keywords: alanine aminotransferase (ALT), aspartate aminotransferase (AST), alcohol, malaria

\section{Introduction}

Malaria is still a major health problem in Indonesia, particularly in Papua. ${ }^{1}$ Based on Indonesia Ministry of Health data in 2013, Papua was the top five provinces with the highest incidence and prevalence of malaria. ${ }^{2}$ The main symptoms of malaria are known as the malaria triad e.g., fever, anemia, sweating. Symptoms of fever can be treated with paracetamol. ${ }^{3}$

Paracetamol induced hepatotoxicity is still a problem in malaria therapy, especially in patients with a history of alcohol consumption. A study conducted by Heart found that the administration of paracetamol for 10 consecutive days at a dose of $4 \mathrm{~g} /$ day may increase serum ALT in subjects with a history of moderate alcohol but no clinical signs of liver damage. ${ }^{9} 85 \%$ $90 \%$ of paracetamol would normally be metabolized by glucuronidation or sulfation and excreted through urine. Less than $10 \%$ were metabolized by cytochrome P450 (especially CYP2E1) to form NAPQI reactive metabolites. In a normal condition, NAPQI is rapidly converted to non-toxic metabolites by glutathione (GSH). However, when GSH

Correspondence: Fonny Dinge. Regional Public Hospital of Abepura, Jayapura, Papua, Indonesia. Email: fonny.dinge@gmail.com 
deficiencies occur, e.g., in paracetamol poisoning, chronic alcohol consumption, and malnutrition, NAPQI levels could increase and lead to liver damage. The main mechanism by which NAPQI is considered to be a major cause of liver damage involves the formation of protein complex with the reaction between sulfidryl group that causes mitochondrial dysfunction and cell death, which is similar to the modulation of the innate immune system..$^{4-8}$

The most commonly used markers of liver damage are alanine transaminase (ALT), aspartate transaminase (AST), alkaline phosphatase (ALP), gamma-glutamyl transferase $(\delta-\mathrm{GT})$ and bilirubin. These markers are easily measured photometrically and present in various species. In the studies conducted by Dart et al., AST and ALT levels on the seventh day of administration of paracetamol 4 grams per day showed an increase with an average $20 \mathrm{U} /{ }^{9}{ }^{9}$

The alcohol consumption is particularly high in Papua, one of the malaria endemic region. ${ }^{10}$ Therefore, this study was conducted to investigate the influence of alcohol consumption, age, ethnicity and type of gender towards paracetamol-induced hepatotoxicity in tropica malaria patients at a hospital in Jayapura, Papua, Indonesia.

\section{Methods}

This study was analytic observational study with cross sectional approach. Subjects in this study were patients with diagnosis of tropical malaria and received symptomatic paracetamol therapy in the inpatient wards of the Abepura Hospital. Inclusion criteria were subjects diagnosed with malaria, aged $\geq 18$ years, and received paracetamol as symptomatic therapy at doses of $1500 \mathrm{mg}$ /day for five days. Subjects will be excluded when receiving anti-tuberculosis and antiretroviral therapy that may increase the risk of hepatotoxicity, have received paracetamol within 7 days before admission and patients who are not willing to be involved in the study. This research has obtained the ethical approval of health research of Abepura Hospital with letter number 009/KM/ IV/2015.

The population in this study were all tropical malaria patients in Jayapura City. The target population in this study was tropical malaria patients who were hospitalized at Abepura Hospital Jayapura during April-June 2015. The data collection was conducted by using SMAST questionnaire consisting of 13 questions about the history of alcohol consumptions from patients during the last 12 months. Estimated time required for filling in the questionnaire was 10 minutes.

Paracetamol-induced hepatotoxicity was measured by observing the result of liver function tests (ALT, AST and bilirubin levels). The liver function tests were conducted on the first day of hospitalization and were reassessed after the fifth day. ALT and AST were examined using spectrophotometric detection. In this detection method, the measurement of absorbance changes in NADH concentrations at $340 \mathrm{~nm}$ UV rays is used based on pyruvate reaction with lactate dehydrogenase (LDH). The instrument used is BS300 spectrophotometer (Mindray Biochemical Electronics Co., Ltd).

Preliminary tests of validity and reliability test were conducted to 30 respondents. The data were analyzed using SPSS software version 15.0. The statistical test used is bivariate analysis using chi-square test to compare the difference of observation frequency with expected frequency. Multivariate analysis using logistic regression test to describe the relationship between one or more 
independent variables with the dependent variable dichotomy is the variable that is assumed to have two values which may be 0 or 1 where this condition can be interpreted as having an effect or no effect.

\section{Results and Discussion}

Research on the effect of alcohol consumption on the occurrence of hepatotoxicity has been done to 45 patients of tropical malaria treated in Abepura Hospital. All subjects were subjected to data recording including subject characteristics of age, sex, ethnicity, and alcohol status and performed ALT, AST and bilirubin tests before receiving paracetamol and after the patient was declared to be home (Table 1).

The composition of male and female patients was almost comparable. Most of the patients were Papuan (86.7\%) with age ranged between 18 - 59 years. Most of the patients did not have alcohol consumption history (53.3\%). Alcohol status was determined based on the SMAST questionnaire given to the patient upon admission.

Alcoholic status was determined based on the SMAST questionnaire administered to the patient upon admission. Patients who had signed the informed concent then filled out the questionnaire accompanied by the researcher. From the results of filling questionnaires on 45 subjects, there were 21 patients with alcoholic status and 24 patients with non alcoholic status.

The significance value of Chi-Square equal to ALT 0.547 , AST 0.522 and bilirubin 0.871 bigger than $p$ value significance that is 0.05 . The significance value of the above ChiSquare test is greater than 0.05 , meaning there is no significant influence between alcoholic status and elevated ALT, AST and bilirubin levels in malaria patients receiving symptomatic paracetamol therapy in Abepura District Hospital (Table 2).

Table 1. Subject characteristics $(n=45)$

\begin{tabular}{lcc}
\hline Characteristics & Number (n) & \% \\
\hline Sex & 23 & 51.1 \\
Male & 22 & 49.9 \\
Female & 39 & \\
\hline Race & 6 & 86.7 \\
Papua & & 13.3 \\
Non-Papua & 16 & 35.5 \\
\hline Age (years) & 8 & 17.7 \\
$<25$ & 11 & 24.4 \\
$25-29$ & 3 & 7.1 \\
$30-34$ & 7 & 16.6 \\
$35-39$ & $29.2(10.0)$ & \\
$\geq 40$ & $18-59$ & \\
$\ddot{X}($ SD) & & 46.7 \\
Range & 21 & 53.3 \\
\hline Alcoholic Status & 24 & \\
$(+)$ & & \\
$(-)$ & & \\
\hline
\end{tabular}


Table 2. The effect of alcoholic status on ALT, AST, and bilirubin

\begin{tabular}{|c|c|c|c|c|c|c|c|c|c|}
\hline \multirow{2}{*}{ Variable } & \multicolumn{2}{|c|}{ ALT } & \multirow{2}{*}{$\mathbf{P}$} & \multicolumn{2}{|c|}{ AST } & \multirow{2}{*}{$\mathbf{P}$} & \multicolumn{2}{|c|}{ Bilirubin } & \multirow{2}{*}{$\mathbf{P}$} \\
\hline & Upper & Lower & & Upper & Lower & & Upper & Lower & \\
\hline Alcoholic & 6 & 15 & \multirow{3}{*}{0.547} & 3 & 18 & \multirow{3}{*}{0.522} & 2 & 16 & \multirow{3}{*}{0.871} \\
\hline Non alcoholic & 5 & 19 & & 5 & 18 & & 2 & 16 & \\
\hline Total & 11 & 34 & & 8 & 36 & & 4 & 35 & \\
\hline
\end{tabular}

Multivariate analysis using logistic regression was done in independent variable such as race, sex, and alcoholic status to dependent variable. Race, age, sex and alcohol status did not significantly influenced ALT, AST and bilirubin (Table 3-5) .

In 21 subjects with alcoholic status there were $29 \%$ of subjects with ALT elevation and $21 \%$ in subjects with non-alcoholic status. Increased AST in subjects with alcoholic status by $14 \%$ and non alcoholic subjects by $24 \%$. Increased bilirubin levels in subjects with alcoholic status by $10 \%$ and in non alcoholic status by $8 \%$.

The ALT and AST enzymatic activity were measured using photometric method and expressed by U/L unit. Bilirubin levels are expressed in units of $\mathrm{mg} / \mathrm{dl}$. Subjects were 45 people who were malaria patients who were hospitalized in Abepura Hospital. In this study the paracetamol dose used by the patient was in a therapeutic dose of $1500 \mathrm{mg} /$ day $(1.5 \mathrm{~g} /$ day $)$ for five days of therapy. In this study the patient's alcoholic status was determined through a SMAST questionnaire resulting 21 subjects were found with alcoholics and 24 patients with nonalcoholic status. Observations on ALT, AST and bilirubin levels were performed at the time of admission (at the the first day) and when the patient was given paracetamol therapy (at the fifth day).

The ALT, AST and bilirubin data were tested on its normality using Saphiro-Wilk test which resulted that they were not normally distributed. The Chi-Square test result showed that the alcoholic status of the patient did not give significant influence to the changes of ALT, AST and bilirubin levels.

In a study aimed at evaluating the effect of race on alcohol-consuming subjects, it showed significant difference in ALT and AST activity in the Hispanic-American race compared to African-American race. ${ }^{12}$ ALT levels showed a decrease in elderly subjects with influencing factors such as gender, alcohol use, and body mass index. ${ }^{13}$

Table 3. Effect of age, race, sex and alcoholic status on ALT level

\begin{tabular}{ccccccc}
\hline \multirow{2}{*}{ Variable } & \multirow{2}{*}{ B } & \multirow{2}{*}{ S.E. } & \multirow{2}{*}{ P* Value } & \multirow{2}{*}{ OR } & \multicolumn{2}{c}{$\mathbf{9 0} \%$ C.I.for OR } \\
\cline { 5 - 7 } & & & & & Lower & Upper \\
\hline Alcoholic & 0.484 & 0.943 & 0.608 & 1.622 & 0.344 & 7.656 \\
\hline Race & -0.906 & 1.030 & 0.379 & 0.404 & 0.074 & 2.201 \\
\hline Sex & 0.612 & 0.894 & 0.494 & 1.844 & 0.423 & 8.028 \\
\hline Age & -0532 & 0.424 & 0.210 & 0.587 & 0.293 & 1.180 \\
\hline Constant & 1.776 & 1.726 & 0.303 & 5.908 & & \\
\hline
\end{tabular}

*) : Logistic Regresion, significance if $\mathrm{p}<0.1$ 
Table 4. The effect of age, race, sex and alcoholic status on AST level

\begin{tabular}{ccccccc}
\hline \multirow{2}{*}{ Variable } & \multirow{2}{*}{ B } & \multirow{2}{*}{ S.E. } & \multirow{2}{*}{ P* Value } & \multirow{2}{*}{ OR } & \multicolumn{2}{c}{$\mathbf{9 0} \%$ C.I.for OR } \\
\cline { 6 - 7 } & & & & & Lower & Upper \\
\hline Alcoholic & 0.226 & 1.079 & 0.834 & 0.798 & 0.135 & 4.702 \\
\hline Race & 0.021 & 1.252 & 0.987 & 1.021 & 0.130 & 8.004 \\
\hline Sex & 0.033 & 1.017 & 0.974 & 1.034 & 0.194 & 5.509 \\
\hline Age & -0.903 & 0.493 & 0.067 & 0.405 & 0.180 & 0.912 \\
\hline Constant & 3.925 & 2.241 & 0.080 & 50.666 & & \\
\hline *) : Logistic Regresion, significance if $\mathrm{p}<0.1$ & & &
\end{tabular}

*) : Logistic Regresion, significance if $\mathrm{p}<0.1$

The incidence of hepatotoxicity in this study was low where elevated ALT, AST and bilirubin levels were not significant after paracetamol symptomatic therapy. This results was supported by a review of Marzilawaty et al with 1024 cases of paracetamol poisoning in Asia, which revealed the incidence of hepatotoxicity was low ie 75 cases or $7.3 \% .18$ In this study the amount of paracetamol dose received by the subject varies on the first day. The amount of dose varied between one to three grams for 24 hours. The second day and so on until the patient comes home on the fifth day, the patients were given orally paracetamol 1.5 $\mathrm{g} / 24$ hours.

Clinical practitioners often require intravenous analgesic and antipyretic administration due to the severity of the patient's condition. The use of i.v. analgesic has been used since 2008 where it is particularly effective for patients who can not swallow or require rapid onset of action. ${ }^{13}$ In the previous studies, therapeutic dose of paracetamol $>4 \mathrm{~g}$ /day given for more than 4 days may lead to elevated ALT levels in subjects with alcoholic status. ${ }^{20}$ In 45 subjects who participated in this study, 11 subjects experienced ALT level elevation with one subject having an increase of $4 \mathrm{x}$ ULN (198 U/l) with alcoholic status and ten other subjects experiencing an increase of $<1 \times$ ULN. Ten subjects with ALT elevation consisted of five subjects with alcoholic status and five subjects with non alcoholic status. Eight subjects experienced an increase in AST in a subject with alcoholic status increased $>$ $8 \times \operatorname{ULN}(532 \mathrm{U} / \mathrm{l})$ and seven others increased $<1 \times$ ULN. Two subjects with alcoholic status and five subjects with non alcoholic status. Four subjects had elevated bilirubin with one subject with alcoholic status increased 2 -fold from the normal value $(0.1 \mathrm{mg} / \mathrm{dl})$ of $0.71 \mathrm{mg} / \mathrm{dL}$. Three other subjects had

Table 5 Effect of age, race, sex and alcoholic status on bilirubin level

\begin{tabular}{ccccccc}
\hline \multirow{2}{*}{ Variable } & B & S.E. & \multirow{2}{*}{$\mathbf{p}^{*}$ Value } & \multirow{2}{*}{ OR } & \multicolumn{2}{c}{$\mathbf{9 0}$ \% C.I.for OR } \\
\cline { 6 - 7 } & & & & Lower & Upper \\
\hline Alcoholic & -0.951 & 1.343 & 0.479 & 0.386 & 0.042 & 3.514 \\
\hline Race & 19.268 & 19297.022 & 0.999 & $2 \mathrm{E}+008$ & 0.000 & \\
\hline Sex & 1.676 & 1.405 & 0.233 & 5.342 & 0.530 & 53.863 \\
\hline Age & 0.052 & 0.594 & 0.930 & 1.054 & 0.397 & 2.800 \\
\hline Constant & -18.233 & 19297.022 & 0.999 & 0.000 & & \\
\hline *): Logistic Regresion, significance if $\mathrm{p}<0.1$ & & & &
\end{tabular}


Table 6. Increased AST, ALT and bilirubin levels on alcoholic status

\begin{tabular}{|c|c|c|}
\hline Variable & Alcoholic $(n=21)$ n (\%) & Non alcoholic $(n=24) n(\%)$ \\
\hline ALT & $6(29 \%)$ & $5(21 \%)$ \\
\hline AST & $3(14 \%)$ & $5(24 \%)$ \\
\hline Bilirubin & $2(10 \%)$ & $2(8 \%)$ \\
\hline
\end{tabular}

increased bilirubin more than two times ie one subject with alcoholic status and two subjects with non alcoholic status. However, the Chi-Square test showed no significant effect between ALT, AST and bilirubin levels before and after paracetamol therapy.

Furthermore, a logistic regression test was conducted to determine the effect of age, sex and sex factors on changes in ALT, AST and bilirubin levels. In the analysis performed on changes in AST levels seen that the age variables had a significant influence on changes in AST ( $p$ 0.067). A study conducted by Le Couteur et al. in 1637 male participants over 70 years recorded levels of ALT, $\delta$-GT, bilirubin and albumin (AST recorded when levels greater than $10 \mathrm{IU} / 1)$. The results showed that ALT and albumin were significant associated with age, in which low ALT lever found in very old age groups. The AST levels in 635 partisans (38\%) were described to have the same activity as ALT which meant AST levels also decreased at older age. ${ }^{14}$ Changes in bilirubin levels did not show any significant effect on age. In this study changes in AST levels that occur was decrease in AST levels in 18 alcoholic subjects and 18 non-alcoholic subjects.

\section{Conclusion}

There was no increased hepatotoxicity effect observed during alcohol consumption (ALT, AST, bilirubin changes) on paracetamol therapy of malaria patients.

\section{References}

1. Provincial Health Office of Papua. The
Health Profile of Papua. 2011.

2. Rummack B, Heard K, Green J, Albert $\mathrm{S}$, Bartelson B, Bodmer M, et al. The effect of acetaminophen on serum alanine aminotransaminase activity in subjects who consume ethanol: a systematic review and meta-analysis of published randomized, controlled trials. Pharmacotherapy. 2012;32(9):784-791.

3. Sabate M, Ibanez L, Eulalia P, Vidal X, Buti M, Xiol X, et al. Paracetamol in therapeutic dosages and acute liver injury: causality assessment in prospective case series. BMC Gastroenterology. 2011;11: 80.

4. Al-Haorini K, Mansi R, Pettie J, Dow M, Bateman DN, Dear JW. The predictive value of hospital admission serum alanine transaminase activity in patients treated for paracetamol overdose. QJ Med. 2013;106:541-546.

5. Heard K, Green JL, Bailey E, Bogdan GM, Dart RC. A randomized trial to determine the change of alanine aminotransferase during 10 days of paracetamol (acetaminophen) administration in subjects who consume moderate amounts of alcohol. Alimentary Pharmacology \& Therapeutics.2007;26:283-290.

6. Jaeschke H, Williams CD, Ramachandran A, Bajt ML. Acetaminophen hepatotoxicity and repair: the role of steril inflammation and innate immunity. Liver International. 2011;32(1): 8-20.

7. Lee KK, Imaizumi N, Chamberland SR, Alder NN, Boelsterli UA. Targeting mitochondria with methylene blue protects mice against acetaminophen- 
induced liver injury. Hepatology. 2014;61(1):326-336.

8. Stranges S, Feudeheim JL,Muti P, Farinaro E, Russel M, Nochajski TH, Trevisan M. Greater hepatic vulnerability after alcohol intake in African Americans compared with Caucasians: A population based study. Journal of the National Medical Association. 2004;96(9):11851192.

9. Le Couteur DG, Blyth FM, Creasey HM, Handelsman DJ, Naganathan V, Sambrook PN, et al. The Associoation of alanine transaminase with aging, frailty and mortality. The Journal of Gerontology Series. 2010;65A(7):712-717.

10. $\mathrm{Hu} \mathrm{Z}$, Lausted $\mathrm{C}$, Yoo $\mathrm{H}$, Yan $\mathrm{X}$, Brightman A, Chen J, et al. Quantitative liver-spesific protein fingerprint in blood: A signature for hepatotoxicity. Theranostics. 2014;4(2):215-228.

11. Dart RC, Green JL, Kufner EK, Heard K, Sproule B. The effect of paracetamol (acetaminophen) on hepatic tests in patiens who chronically abuse alcohol -a randomized study. Alimentary Pharmacology and Therapeutics. 2010;32:478-486.

12. Torkadi PP, Apte IC, Bhute AK. Biochemical evaluation of alcoholic liver disease and non-alcoholic liver disease. Indian Journal of Clinical Biochemistry. 2014;29(1):79-83.

13. Marzilawaty RR, Ngau YY, Mahadeva S. Low rates of hepatotoxicity among Asian Patients with paracetamol overdose: a review of 1024 cases. BMC Pharmacology and Toxicology. 2012; 13(8):1-7.

14. Peacock WF, Breitmeyer JB, Pan C, Smith WB, Royal MA. A randomized study of the efficacy and safety of intravenous acetaminophen compared to oral acetaminophen for the treatment of fever. Academic Emergency Medicine. 2011;18(4):360- 364. 